\title{
Effects of Nonthermal Plasma on Wheat Grains and Products
}

\author{
V. Scholtz $\mathbb{D}^{1},{ }^{1}$ B. Šerá, ${ }^{2}$ J. Khun, ${ }^{1}$ M. Šerý, ${ }^{3}$ and J. Julák ${ }^{4}$ \\ ${ }^{1}$ University of Chemistry and Technology in Prague, Department of Physics and Measurements, Technická 5, Praha, \\ Czech Republic \\ ${ }^{2}$ Comenius University in Bratislava, Faculty of Natural Sciences, Department of Landscape Ecology, Ilkovičova 6, \\ Bratislava 842 48, Slovakia \\ ${ }^{3}$ University of South Bohemia, Faculty of Education, Department of Physics, Jeronýmova 10, České Budějovice, Czech Republic \\ ${ }^{4}$ Charles University and General University Hospital in Prague, First Faculty of Medicine, \\ Institute of Immunology and Microbiology, Studničkova 7, Praha, Czech Republic \\ Correspondence should be addressed to V. Scholtz; vladimir.scholtz@vscht.cz
}

Received 17 January 2019; Revised 10 April 2019; Accepted 7 May 2019; Published 12 June 2019

Academic Editor: Vera Lavelli

Copyright (c) 2019 V. Scholtz et al. This is an open access article distributed under the Creative Commons Attribution License, which permits unrestricted use, distribution, and reproduction in any medium, provided the original work is properly cited.

\begin{abstract}
This paper presents the review of effects of nonthermal plasma (NTP) treatment on both the wheat grains and flour with potential to be applied in practice. The NTP can be used in wheat grain surface disinfection, grain germination and vitality improving, and wheat flour modification and disinfection. NTP causes effective decontamination from bacteria and fungi together with insect pests and causes minimal damage to wheat grains; it inactivates enzymes and enhances the grain shelf life; it enhances the germination and initial state of growth resulting in the increase of final yield. Moreover, the production of qualitatively better dough is also mentioned.
\end{abstract}

\section{Introduction}

Nonthermal plasma (NTP) has been constituted in biotechnology as an alternative method for food processing and as an emerging antimicrobial technology for inactivation of undesirable microflora. Moreover, it has been found that NTP affects also other parameters of both treated inorganic and biological objects. In the last decade, NTP treatment of grains has been established as a possible new field of interest. Examples of these approaches may be found in [1-4].

The cereals are the main ingredient of human food, where only grains are used for human nutrition $[5,6]$. The grains are consumed either whole or ground to flour, which exhibits different final granulation and/or chemical composition. Wheat is one of the world's leading food crops and is one of the most grown cereals [5] as a source of white wheat products: white bread, toasts, baguettes, hamburgers, croissants, and pizza's dough. The possibilities of NTP treatment of wheat grains in agrotechnical practices have been studied by many scientific teams in the one recent decade. The significance and impact of such studies is undoubtedly significant for better preservation of cereals for nutrition. However, the existing NTP applications for this purpose suffer from inconsistent methodologies, making it impossible to compare and select the optimal methodology. Therefore, our goal here is not to determine the best method, but rather to enumerate the options used so far.

In this review, we would like to present summarized results of several studies of NTP treatment of wheat grains to demonstrate the new possible ways of affecting its properties. We have chosen the wheat grain as one of the world's most important nutritive with wide amount of published studies. Further, it is possible to predicate similar NTP affections of other species of cereals also. In general, for clarity, we want to give up describing the optimization of each NTP source and its many regimes for specific application. Hence, we decided to focus mainly on the possible effects of NTP on wheat rather than on the detailed description of plasma generation and other treatment details. We assume that friendly reader would be interested especially to the list of interesting and curious effects of NTP and that they may find the details in referred works. The description of plasma 
effects presented here begins at the surface of wheat grain and stepwise continues through the growth characteristics, metabolisms, and matured plants to the flour as the final food product.

\section{Nonthermal Plasma Technology}

The term "NTP" typically denotes the state of ionized gas at ambient temperature with dominant collective behavior of charged particles. It has been the subject of many previous reviews and books, e.g., [7-9]. A nice introduction into plasma and its generation is also presented in the book devoted to plasma medicine [10] or in the review [11]. The common ways to get NTP are electrical discharges, which have been also reviewed for many times, e.g., [10-12]. The brief description of the most frequently used approaches is as follows.

Corona discharge (CD) is typically generated by high voltage on sharp electrodes, such as tips, pinpoints, or thin wires. The electric field is formed close to such points, and the active region of corona and plasma generation arises. Corona discharge active region appears only close to the point electrode, and it is limited up to units of $\mathrm{mm}$. Several modifications of corona-based discharges were tested, e.g., by Khun et al. [13].

Dielectric barrier discharge (DBD) is an alternating current discharge burning typically between two electrodes separated by dielectric material, which avoids the charged particle transport between electrodes. The discharge burns due to the alternating polarization of dielectric and by the electric induction only. In contrast to corona, the DBD electrodes may be constructed as planes, and therefore, the plasma area is limited just by the power of high voltage supply. A brief description of this method may be found, e.g., in [14].

Radio frequency (RF) and microwave discharges (MDs) are generated by high frequencies $(\mathrm{MHz}$ and $\mathrm{GHz})$ electromagnetic induction or waves in a resonance box. MDs are often used in the basic research of NTP interactions with biomaterials. For further information, see [15].

Plasma jet (PJ) represents a special configuration of previously described discharges. The active particles from the active region are transmitted through the electrode area by flowing auxiliary gas, forming a stream of active particles burning as a small jet. Typical sources are called plasma jet, plasma pen, plasma torch, or plasma needle. They allow the local application and higher powers. For review, see [16].

Cometary DC discharge $[17,18]$ resembles plasma jet, but needs no auxiliary gas supply. The insertion of insulated metallic grid improves the inactivation efficiency and size of the treated area [19].

Despite the fact that each discharge is unique and therefore the generalization of results is difficult or impossible, there is a prevailing consensus about the possible mechanisms of NTP affection of the treated object. For a brief overview of this topic, see [20]. In the active discharge area, many active particles are generated from the molecules or atoms of discharge atmosphere. In air or similar atmospheres, the nitrogen active particles, often denominated as reactive nitrogen species (RNS), and the oxygen active particles, often denominated as reactive oxygen species (ROS), are generated. The dominant active particles are radicals such as electronically and vibrationally excited oxygen $\left(\mathrm{O}_{2}{ }^{*}\right)$ and nitrogen $\left(\mathrm{N}_{2}{ }^{*}\right)$. The active forms such as atomic oxygen $(\mathrm{O})$, singlet oxygen $\left({ }^{1} \mathrm{O}_{2}\right)$, superoxide anion $\left(\mathrm{O}_{2}{ }^{-}\right)$, atomic nitrogen $(\mathrm{N})$, excited nitrogen $\left(\mathrm{N}_{2}(\mathrm{~A})\right)$ and $\mathrm{H}_{2} \mathrm{O}^{+}, \mathrm{OH}^{-}$anion, and $\mathrm{OH}^{-}$are also important. The stable molecules such as ozone $\mathrm{O}_{3}$, nitric oxide $\left(\mathrm{NO}_{x}\right)$, and hydrogen peroxide $\left(\mathrm{H}_{2} \mathrm{O}_{2}\right)$ are generated, too. This extensive field has been reviewed several times, e.g., in [21, 22].

\section{Wheat Grains after NTP Treatment}

The application of various chemical insecticides and fumigants during grain storage has caused numerous problems, including the accumulation of pesticides and fumigant residues in treated grains [23]. Another serious problem is the development of insecticide resistance in stored grain insect pests [24]. Therefore, there has been growing interest in biotechnology research concerning the possible using of some alternative treatments, such as plant extracts [25], gamma irradiation [26] or plant extract and gamma irradiation together [27], laser [28], or NTP treatment [29-31]. Some earlier attempts to describe the effects of NTP on various seeds, including wheat, have been evaluated in the review [32]. In addition to direct plasma exposure, the action of water previously exposed to NTP (so-called plasmaactivated water, PAW) was also reported by Kučerová et al. [33]. The PAW improved germination, early development of the seedlings, the content of photosynthetic pigments in the leaves, and soluble protein content in the roots and suppressed the activity of antioxidant enzymes.

The NTP experiments reported in this section have a common general scheme consisting of dry wheat grains exposure for appropriate time, followed by the analysis of resulting properties. For better clarity, the quoted works and their brief content are also summarized in Table 1.

This summary shows that it is very difficult not only to compare individual results but also to determine the optimal methodology for influencing wheat seeds and products. Various authors employed almost all possible plasma sources (except plasma jet), differing in nature and properties. Different experimental conditions were also used, namely, the exposure times ranging from 10 seconds to 45 minutes.

3.1. Surface Decontamination. The surface of the cereal grains can be contaminated by both the microorganisms and germs of various insect pests [34]. The following works indicate NTP to be a promising tool for effective decontamination offering a wide range of possible applications including inactivation of surface microorganisms and germs of insect pests on cereal grains, above all epiphytic bacteria.

The exposure of winter wheat grains to NTP reduces the fungal colonies' number by one order; as reported by Kordas et al. [35], the optimal exposure time was $10 \mathrm{~s}$. Los et al. [36] found this decrease by two orders. Zahoranová et al. [37] 
TABLE 1: Experimental conditions and results of some attempts to influence wheat grains and flour properties.

\begin{tabular}{lcc}
\hline Discharge description & Exposure time & Results \\
\hline DBD, atmospheric pressure, air, $80 \mathrm{kV}, 50 \mathrm{~Hz}$ & $20 \mathrm{~min}$ & $\begin{array}{c}\text { Bacteria and fungi reduction of } 2.5 \mathrm{log}_{10} \\
\text { Grain surface hydrophobicity decreased } \\
\text { Minimal or negative influence on germination }\end{array}$ \\
\hline [36] & $\begin{array}{c}1 \log _{10} \text { reduction of natural bacteria and } 2 \log _{10} \\
\text { reduction of filamentous fungi } \\
\text { Grain water uptake increased }\end{array}$ \\
DB, atmospheric pressure, air, AC $20 \mathrm{kV}, 14 \mathrm{kHz}$ & $0-120 \mathrm{~s}$ & $\begin{array}{c}\text { Germination increased, optimum at 30 s, over 70 s [37] } \\
\text { lower than control }\end{array}$
\end{tabular}

DBD, atmospheric pressure, air, AC $20 \mathrm{kV}, 14 \mathrm{kHz} \quad 0-120 \mathrm{~s}$

$\mathrm{DBD}$, atmospheric pressure, air, $\mathrm{AC} 10 \mathrm{kV}$, ca $13 \mathrm{kHz}$

$20 \mathrm{~s}$

DBD, atmospheric pressure, air, $17 \mathrm{kV}, 50 \mathrm{~Hz}$

$4 \mathrm{~min}$

DBD, atmospheric pressure, air, AC $13 \mathrm{kV}, 50 \mathrm{~Hz}$

$13 \mathrm{~min}$

$\mathrm{DBD}$, atmospheric pressure, air, $\mathrm{AC} 15 \mathrm{kV}$ in amplitude, $50 \mathrm{~Hz}$

5-30 $\min$

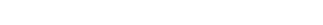

$5-30 \mathrm{~min}$
Germination increased, optimum at $30 \mathrm{~s}$, over $70 \mathrm{~s}$ lower than control

Increase in dry weight and vigor index, optimum for $30 \mathrm{~s}$

Significant reduction of microbial contamination No or negative (over $20 \mathrm{~min}$ ) influence on germination

Total reduction of larvae of flour beetles Tribolium confusum and Ephestia kuehniella

No significant changes in fat, protein, ash, and moisture content of flour

Improvement of water uptake of grain surface Germination potential, germination index, germination rate, and vigor index increased Shoot length, root length, dry weight, and fresh weight increased

Penetrating of active species into grains improves soluble protein content and $\alpha$-amylase activity

Etching effect on the grain surface; improvement of water uptake

Germination potential, germination rate, germination index, and vigor index increased

Root length, shoot length, fresh weight, and dry weight of the seedlings increased, optimum at $7 \mathrm{~min}$

Enhanced the osmotic-adjustment products and proline and soluble sugar contents

Grain wettability increased

Minimal influence on germination

Longer roots and sprouts and heavier roots increase of the $\mathrm{R} / \mathrm{S}$ ratio

36]

Improved the germination rate, speed of germination, and speed of growing in the early stage; over $30 \mathrm{~min}$ properties decreased under untreated

DBD, atmospheric pressure, air, $\mathrm{AC} 18 \mathrm{kV}$
amplitude, $50 \mathrm{~Hz}$

Improved length of roots and sprout, vigor index, number of roots; over $30 \mathrm{~min}$ decreased under control

Improved germination rate and seedling vigor Decrease of root length and root dry weight;

DBD, low pressure 10 torr, $\mathrm{Ar} / \mathrm{O}_{2}$ and $\mathrm{Ar} / \mathrm{Air}$, $5-10 \mathrm{kV}, 3-8 \mathrm{kHz}$

$90 \mathrm{~s}$ increase of shoot length and shoot dry weight Increase of soluble proteins in both roots and shoots

DBD atmospheric pressure, air, $10 \mathrm{kV}, 6 \mathrm{kHz}$ and up to $24 \mathrm{kV}, 50-\mathrm{Hz}$

$\mathrm{DBD}$, variable gas or air, $0.5-3 \mathrm{kV}, 50 \mathrm{~Hz}$, from low pressure under $1 \mathrm{mbar}$ to atmospheric pressure

5-35 min

Reduction of lipase and lipoxygenase enzymes activity; enhance the shelf life of grains $100 \%$ mortality of Tribolium castaneum beetle No significant changes in color of flour

Elastic and viscous moduli of dough from strong wheat flour increased; no variation in the DBD atmospheric pressure, air, 60-70 kV 5 and $10 \mathrm{~min}$ dissipation factor $\tan \delta$; improvement of the dough strength

Reduced development of Rhizopus nigricans fungal disease
$3 \min$ 
TABle 1: Continued.

\begin{tabular}{|c|c|c|c|}
\hline Discharge description & Exposure time & Results & Paper \\
\hline $\begin{array}{l}\mathrm{DBD} \text { at } 0-50 \mathrm{kV} \text { and } 50 \mathrm{~Hz} \text { in the } \mathrm{Ar}, \mathrm{N}_{2} \text {, air, or } \mathrm{O}_{2} \\
\text { atmosphere }\end{array}$ & $1-19 \min$ & $\begin{array}{l}\text { Cleaning of the seeds surface } \\
\text { Germination potential increased } \\
\text { Etching effects on the seed coat } \\
\text { Shoot and root length increased } \\
\text { Increase of soluble protein production }\end{array}$ & [59] \\
\hline $\mathrm{DBD}$ in air, $80 \mathrm{kV}, 50 \mathrm{~Hz}$ & 30,60 , or $180 \mathrm{~s}$ & $\begin{array}{c}\text { Germination rate enhanced } \\
\text { Positive effects on seedling growth } \\
\text { Changes of seed surface in seed } \mathrm{pH} \text {, nitrites, } \\
\text { nitrates, and malondialdehyde content }\end{array}$ & {$[36]$} \\
\hline Not specified, probably DBD, atmospheric air & $120 \mathrm{~s}$ & $\begin{array}{l}\text { No change in the total count of aerobic bacteria and } \\
\text { mould in flour } \\
\text { Total free fatty acids and phospholipids reduced; } \\
\text { some oxidation markers increased } \\
\text { Treated flour did produce a stronger dough }\end{array}$ & {$[67]$} \\
\hline $\begin{array}{l}\mathrm{DBD} \text { at } 6-10 \mathrm{kV}, 5-15 \mathrm{kHz} \text { in the } \mathrm{Ar} \text { at } \\
\text { atmospheric pressure }\end{array}$ & $0-60 \mathrm{~min}$ & $\begin{array}{c}\text { Inactivation of bacterial G. stearothermophilus } \\
\text { endospores }\end{array}$ & {$[40]$} \\
\hline Low-pressure plasma & $15 \mathrm{~s}$ & $\begin{array}{l}\text { Spike length and number of grains per ear } \\
\text { improved; grain weight increased by } 1 \%\end{array}$ & {$[65]$} \\
\hline Low pressure $140 \mathrm{~Pa} \cdot \mathrm{MW}$ discharge & $3-40 \mathrm{~min}$ & $\begin{array}{c}\text { Longitudinal cracks and fast wetting of grain } \\
\text { surface } \\
\text { Germination enhanced } \\
\text { Shoot phenolic compounds increased }\end{array}$ & {$[43]$} \\
\hline $\begin{array}{l}\text { Plasma discharge at frequency } 3109 \mathrm{MHz} \text {, power } \\
60 \mathrm{~W}, 80 \mathrm{~W} \text {, and } 100 \mathrm{~W} \text {, helium atmosphere }\end{array}$ & $15 \mathrm{~s}$ & $\begin{array}{c}\text { Improving seed germination potential and } \\
\text { germination rate } \\
\text { Improving plant height, root length, and fresh } \\
\text { weight } \\
\text { Higher chlorophyll content, nitrogen, and } \\
\text { moisture content }\end{array}$ & {$[58]$} \\
\hline
\end{tabular}

One-order decrease of fungal colonies

$\mathrm{CD}$, atmospheric pressure, air, $\mathrm{AC} 8 \mathrm{kV}$, $0.1-83 \mathrm{kHz}$

$10 \mathrm{~s}$
No significant differences on lengths of the root and shoot and on weight of the seedling

No significant differences in dry matter of plants' root length decreased to cca one-half

Grain surfaces more rough; enhanced water permeability into the grains

Gliding arc discharge, atmospheric pressure, $\mathrm{H}_{2} \mathrm{O}$ / air, $\mathrm{H}_{2} \mathrm{O} / \mathrm{O}_{2}, \mathrm{H}_{2} \mathrm{O} / \mathrm{O}_{2} /$ air, $5 \mathrm{kV}$

3-15 min

Positive (till $6 \mathrm{~min}$ ) and negative (over $6 \mathrm{~min}$ )

influence on germination and plant length
Increase in total number of grain per spike, grain weight, and yield

Enhancement of water absorption property; increased germination rate

Glow discharge, $1-6 \mathrm{kV}, 3-5 \mathrm{kHz}$, low pressure $1.3 \mathrm{kPa}$, air, and air $+\mathrm{O}_{2}$

3-15 $\min$

Increase of dry weight, spike length, number of spikelet, and number of grains

Yield increased by $\sim 20 \%$ from plants

RF $13.56 \mathrm{MHz}$, air or air + He mixture, low pressure $30-200 \mathrm{~Pa}$

$90 \mathrm{~s}$ Germination increased Lengths of root and shoot and dry weight increased

Improved germination and development of the seedlings

Plasma-activated water produced by a transient spark discharge
Activation time
$1-40 \mathrm{~min}$
Improved content of photosynthetic pigments in

Suppressed activity of antioxidant enzyr

]


argon atmospheric plasma for inactivation of Geobacillus stearothermophilus endospores for artificially contaminated wheat grains and polypropylene model substrates. While smooth substrates were decontaminated effectively with reduction of more than 4 magnitudes, the reduction on grain surface was of one magnitude only. The authors considered that the endospores are shielded from plasma-generated reactive species by uneven surface, loose pieces of bran, and the ventral furrow of wheat grains.

Insects are important pests; their decontamination has been reported by Shahrzad et al. [41], who treated 2-3 instar larvae among wheat grains. The mean percentage of mortality reached $100 \%$ after $20 \mathrm{~s}$ for both the pests called confused flour beetle (Tribolium confusum, Coleoptera: Tenebrionidae) and Mediterranean flour moth (Ephestia kuehniella, Lepidoptera: Pyralidae). Similar results were found also in an experiment reported in [42], where egg, larval, and adult stages of red flour beetle (Tribolium castaneum, Coleoptera: Tenebrionidae) were treated by NTP. In all flour beetles' stages, $100 \%$ mortality can be achieved depending on plasma exposure time and plasma intensity. Optimal effect of plasma with an impact on all stages of $T$. castaneum was observed for 15 minutes.

This review demonstrates that NTP technology is a promising tool for effective decontamination, which offers a wide range of possible applications including inactivation of surface microorganisms and germs of insect pests on cereal grains.

3.2. Surface Property Affection. Together with the surface decontamination, the affection of surface properties should be expected. It is curious that these expected side effects are generally positive.

The NTP treatment caused cracks occurring on wheat grain surface, which led to the improvement of water uptake, subsequently benefiting its germination [43]. After NTP treatment, the mean water uptake was $41 \%$ in the control sample and $57 \%$ in the exposed one [44]. Similar etching effect, resulting in the improvement of its water absorption capacity, was reported by Li et al. [45]. Also, Rahman et al. [42] stated that the surface of wheat grains was much rougher in exposed grains as compared to that of control ones. Further, the grain coat becomes eroded and chapped after NTP. Similarly, Roy et al. [46] found that NTP treatment caused noticeable morphological changes on seed surface and consequently slightly increased absorption of water. Also, Zahoranová et al. [37] showed that wheat grains treated with NTP took more water than the untreated ones, increasing exposure dose of plasma also increased the water uptake.

The surface hydrophobicity of wheat grains after different applications of NTP was measured by Los et al. [36]. They found that surface hydrophobicity decreased after direct NTP treatment and remained unaffected in the case of indirect treatment. Dobrin et al. [47] also showed interest in wheat grain wettability; they found that the contact angle measured between grain surface and water drop was $92^{\circ}$ on the untreated grains, and it decreased to $53^{\circ}$ on treated grains. The water absorption was higher in the case of the treated grains as compared with the control samples, too. Likewise, Roy et al. [48] recognized that the surfaces of the treated wheat grains become rough with respect to the control. The changes of surface erosion and roughness may be associated with the enhanced water permeability into the grains. The best water absorption effect (27\% more than in control) was found after 12 minutes of NTP treatment. This surface wetting is an important precondition of faster seeds wetting and germination [31], as described in the next section.

\subsection{Seed Germination and Seedling Initial Growth. The NTP} treatment of grains significantly influences germination and initial growth of plants. The characteristics observed in the experiments included several parameters such as number of germinated grains, germination rate, speed of germination, germination index, grain vitality, length and weight of seedlings, root/shoot (R/S) ratio, and many others. However, the authors usually do not provide their explicit definitions, so we refer to them as they are presented in the original papers.

The germination of many plant species can be improved by NTP treatment. The positive effect of NTP was found on barley (Hordeum vulgare, [49]), maize (Zea mays, [50]), oat (Avena sativa, [51]), rice (Oryza sp., [52]), spinach (Spinacia oleracea L. Beiouzhizun, [53]), bell pepper (Capsicum annuum L. cultivar California Wonder, [54]), and mung bean [55]. On the other hand, the neutral effect was found on oat germination and early growth [43].

Probably, the first researches on wheat grains germination under the effect of different physical factors (ionizing, laser, and NTP) were recorded in the 80s of the last millennium and reported in [56, 57], as mentioned in [51]. Intensity of the initial germination was improved at the expense of accumulation of germ mass; an increase of root length and mass were observed. Under the influence of all physical factors used, field germination increased from $4 \%$ to $22 \%$ depending on weather conditions.

Šerá et al. [43] tested wheat grains from a private collection, where the grains had been stored for 15 years in dry place before the experiment. Significant difference was found in seed germination at the 4th day of cultivation between a control sample (0\%) and the $180 \mathrm{~s}$ NTP-treated sample $(6 \%)$. Above all, the treated grains started to germinate at the 4th day and control grains at the 8th day.

Treatment by cold helium plasma of $80 \mathrm{~W}$ could significantly improve germination potential $(6.0 \%)$ and germination rate $(6.7 \%)$ of wheat seed. At the seedling stage, plant height (20\%), root length $(9.0 \%)$, and fresh weight (22\%) were improved significantly, also the chlorophyll content $(9.8 \%)$, nitrogen $(10.0 \%)$, and moisture content (10.0\%) were higher than those of the control [58].

Similar results were also reported by Meng et al. [59] using DBD plasma with various surrounding gases (oxygen, air, argon, and nitrogen), and they observed significant increase of germination potential by $24.0,28.0$, and $35.5 \%$ after 4 minutes of exposure. 
In the work of Guo et al. [44], the germination potential, germination index, and vigor index of wheat grain significantly increased after NTP treatment by $31 \%, 14 \%$, and $55 \%$ over control, respectively. The mean germination rate increased from $88 \%$ in the control sample to $95 \%$ in the NTPtreated sample. The improved germination rate and seedling vigor of wheat grains were reported also in [42], where the cumulative germination increased from $70 \%$ up to $85 \%$ for control and treated samples, respectively. Zahoranová et al. [37] and Zhang et al. [60] consistently found a significant effect of NTP treatment on the germination rate rising by $21 \%$ and $8 \%$, respectively.

The germination potential, germination rate, germination index, and vigor index increased by $27 \%, 9 \%, 17 \%$, and $47 \%$ after 7 minutes of NTP treatment, respectively [45]. The optimal time of treatment seemed to be 4 minutes, when germination potential significantly increased to $77 \%$ and the germination rate was enhanced to $95 \%$ (in comparisons with $62 \%$ and $88 \%$ of control samples, respectively). The same authors also presented the hypothesis that the changes in the wheat grain germination characteristics suggested an appropriate DBD plasma treatment dose to promote the wheat grain germination. The similar results presented by Gidea et al. [61] showed that the plasma grain treatment for appropriate time improved the germination rate, speed of germination, and speed of growing in the early stage. However, for high NTP doses, i.e., over optimal treatment time (in this case, $30 \mathrm{~min}$ ), all the growing properties decreased under untreated. Also in [48], the grains treated for 3 and 6 minutes had the highest germination rate $95-100 \%$. However, the further increments of NTP treatment time caused the decrease of the germination rate. Similarly, Roy et al. [46] reported that germination rate, germination index, and vigor index increased for all used exposition times and atmospheres, with optimal exposure time of 6-9 min.

On the contrary, other works do not report the enhancement of samples properties. In the study of Los et al. [36], short plasma treatment had minimal influence on the germination rate of wheat; however, extending treatment time up to 20 min negatively affected this qualitative parameter. In the experiment described in [38], the grain germination percentage of samples treated for up to $5 \mathrm{~min}$ was not affected, but it was decreased after 20 min of NTP treatment.

The effects of plasma treatment on wheat seed germination and seedling growth, together with changes in the surface chemistry and characteristics of the wheat seeds exposed to plasma, were investigated by Los et al. [62]. Treatments of 30-60 s significantly enhanced the germination rate and showed positive effects on seedling growth.

Many observed characteristics of seed germination generally showed better parameters, especially at the first days of the seed germination. Seed germination and initial growth of seedlings are closely related, and many authors tested both at once.

In the experiment performed by Dobrin et al. [47], the total length of the root system per wheat grain was obtained by summing the lengths of individual adventive roots of each grain. The distribution of untreated grains was centered at about $33 \mathrm{~cm}$, while that of the treated grains was centered at $36 \mathrm{~cm}$. NTP treatment of wheat grains resulted in a $10 \%$ increase of the mean root length. On the other hand, a very slight increase was obtained in the case of shoot length. Grains treated with NTP for 15 min had substantially heavier roots $(1.06 \mathrm{~g})$ than the control samples $(0.78 \mathrm{~g})$. Shoot weight was about the same in both cases $(0.88 \mathrm{~g}$ and $0.89 \mathrm{~g})$. There were considerable differences between R/S ratios: the control sample had 0.88, while the treated sample had 1.2.

Concerning with germination, Gidea et al. [61] reported also the increase of average length of roots and sprouts and vigor index, but after exposure times over $30 \mathrm{~min}$, all measured properties decreased close to or under untreated ones. In the experiments of Roy et al. [48], plant lengths from grains exposed for 3 and $6 \mathrm{~min}$ increased to $23 \mathrm{~cm}$ and $22 \mathrm{~cm}$, respectively, while the control was $21 \mathrm{~cm}$ at the same incubation period. After 20 days of sowing, the longest plant height was $23 \mathrm{~cm}$ for the exposed seed, while the control was $19 \mathrm{~cm}$. The same author found similar results in the paper [46], where the plant length and dry weight increased for all used exposition times and atmospheres (air and air $/ \mathrm{O}_{2}$ ). Maximum increase of plant length was achieved by $11 \%$ for 6 or 9 min exposures. The significant increase of shoot length, root length, dry weight, and fresh weight of wheat grains was described also in [44].

Significant effects of plasma treatment on growth parameters of wheat seedlings in dry weight (12\% increase) and vigor indexes I and II (28\% and 36\% increase) were measured [37]. Zhang et al. [60] found that the lengths of the wheat root and shoot were increased effectively by $8.7 \mathrm{~cm}$ and $3.3 \mathrm{~cm}$, and the dry weight increased by approximately $10 \%$. Li et al. [45] followed the wheat seedling growth after NTP treatment of grain. They observed that the root length, shoot length, fresh weight, and dry weight of the seedlings increased significantly after different NTP exposures; the exposure optimal for grain growth was probably 7 minutes.

The previously mentioned work of Kordas et al. [35] belongs also in this section: they worked with contaminated wheat grains and did not find any significant differences in shoot lengths and weight of the seedling. On the other hand, they found the rapid decrease in the root length (up to 50\%). Similarly, no significant differences were recorded in the previously mentioned experiment on 15-year-old wheat grains [43].

Characteristics of seed germination under laboratory conditions are usually different from real-field data. All environmental influences cannot be controlled in the field, so real germination and development may differ from laboratory results. In the future, it seems necessary to plan experiments for germination tests in the field as well. Two such studies are mentioned below.

3.4. Biochemical Characteristics, Secondary Metabolites, Stimulations, and Stress Reactions. For the sake of completeness, it should be mentioned that NTP influences several biochemical characteristics of grains. However, due to less number of papers, no generalization or conclusion can be made. Some experiments indicate penetration of active 
species from NTP through the porous seed coat inside the grain, where they react with plant cells (e.g., [43]). We bring further indirect evidence from experiments on wheat grains.

Amount of secondary metabolites represented by phenolic compounds was studied in wheat seedlings after NTP treatment of the grains [43]. Contents of two phenolic compounds from shoot extract of treated wheat grains were increased to $151 \%$ and $165 \%$ in comparison with the control sample. The biggest differences of phenolic compound contents were found in the shoot extract than in root extracts.

No alternations in fat, protein, ash, and moisture content of wheat after NTP treatment were found by Rahman et al. [42] and Shahrzad et al. [41]. Guo et al. [44] reported that the active species from NTP penetrated into the caryopses and activated their physiological reactions, resulting in enhancement of soluble protein content by $15 \%$ and $\alpha$-amylase activity by $51 \%$.

According to Tolouie et al. [63], the lipase and lipoxygenase activities are essential for the enhancement of grain shelf life. The result of this work concluded that NTP inactivates these enzymes and increased the shelf life. The lipase and lipoxygenase activity was reduced after $25 \mathrm{~min}$ exposure to $25 \%$ and $50 \%$ of initial extent, respectively. Increasing exposure time and voltage can enhance the inactivation. However, NTP treatment could not permanently inactivate lipase and lipoxygenase. Despite the recovery of enzymes activity during the storage, the enzyme activity of treated samples was much lower than the untreated ones after 30 days of storage at room temperature.

Furthermore, Iranbakhsh et al. [64] reported the NTPinduced expression of heat shock factor $\mathrm{A} 4 \mathrm{~A}$, improving the wheat growth and slightly increasing the resistance against salt stress. These results concluded that NTP can enhance the shelf life of wheat grains.

3.5. Wheat Production. Previous results show the possibilities of NTP to improve the properties of wheat grains and seedlings. For general impression, the effect of the final product also should be mentioned. If the NTP should be used to treat cereal grains, it is important that the crop production should be higher or at least the same. However, more field experiments to study the effect of NTP treatment on the farm production are needed.

The effects of the NTP treatment of wheat grains on cereal spikes as a final agricultural product are presented in the two following works. He et al. [65] cultivated three different cultivars of wheat grains treated with NTP for $15 \mathrm{~s}$ and sown on the field. The results showed that the spike length and number of grains per spike were improved observably in all tested wheat cultivars. However, the thousand-grain weight and grain protein content increased only by 0.93 g, i.e., by $1 \%$. On the other side, Roy et al. [48] suggested that, beside the increase of germination potential, vigor index, and noteworthy improvement in photosynthetic pigment, the significant increase in the total number of grains per spike, thousand-grain weight, and yield of wheat by $5 \%$ also occurred. Moreover, the same authors [46] reported a yield increase by $\sim 20 \%$.

\section{Wheat Flour after NTP Treatment}

NTP treatment may not be targeted only on cereal grains. Some researchers studied also the effect of NTP treatment of flour and reported several interesting results.

Mahendran [66] confirmed the mortality of adult Tribolium castaneum beetle caused by NTP treatment of wheat flour. This mortality was under specific conditions up to $100 \%$; no changes in the color of the flour were observed (see also Section 3.1).

The potential of cold plasma as a tool to modify wheat flour functionality was confirmed by Bahrami et al. [67]. They found that NTP treatment did not affect the concentration of total nonstarch lipids and glycolipids. This treatment, however, reduced total free fatty acids (extracted by $n$-hexane: diethyl ether 1:1) and phospholipids. Oxidation markers (hydroperoxide value and head space $n$-hexanal) increased with treatment time and voltage of discharge, which confirmed the acceleration of lipid oxidation. The impact of NTP on free fatty acids was due to a reduction in all major fatty acids; this was more evident in the most oxidatively labile fatty acid, and linolenic acid reduced by $100 \%$. Total proteins were not significantly influenced by NTP treatment, although there was a trend towards higher molecular weight fractions, which indicated protein oxidation, and treated flour did produce thicker dough. However, this work reported no change in the total aerobic bacterial count or total fungi count as a result of NTP treatment.

Structural and functional properties of dough prepared from wheat flour after NTP treatment were studied also by Misra et al. [2]. The elastic and viscous moduli of dough and the dough strength increased after the treatment by optimal NTP dose.

\section{Discussion}

Based on the available literature, the authors compiled an overview of the results, demonstrating the relationship between NTP and wheat grains. It was difficult to compare the accumulated results because the apparatus and discharges used are not sufficiently described, as are many measured grain characteristics.

NTP is intensively studied in relation to seed modification, above all in relation to the agriculture $[29,32]$ and food industry $[68,69]$. The strategy of using NTP in the food industry is to decontaminate of food products, packaging material processing, functionality modification of food materials, and dissipation of agrochemical residues [4, 29]. Many microorganisms are sensitive to the NTP. So, the indisputable benefit of using NTP is a safe seed without chemical residua, because effective NTP treatment works with clean air, water vapor, or plasma-activated water [70, 71]. Reviewed works clearly demonstrate that the NTP causes effective decontamination of wheat grains from bacteria, fungi, and insect pests with minimal damage of the grains.

In general, lower treatment times will maintain or even improve seed viability. The seeds of many plant species were vital after short time of NTP treatment; they germinate well, e.g., many grains [49-51, 71, 72]. Usually, wheat grains have 
good vitality after plasma application. Moreover, due to inactivation of several enzymes, plasma treatment can enhance the wheat grain shelf life. Other works demonstrated not only the enhancement of germination and initial state of growth, albeit they suggest a small increase in the final yield.

The NTP treatment may cause negative effect in some plant species in seed germination, because some plant species are probably more sensitive to NTP than wheat grains, e.g., oat (Avena sativa) [43]. Cultivars of both the hemp seeds (Cannabis sativa) [73] and poppy seeds (Papaver somniferum) [74] were affected by NTP in a different way. Some cultivars were positively affected, while others were not. The type of plasma apparatus/discharge and the parameters of the plasma treatment are crucial too. Significant differences were found in the germination and early growth of buckwheat seeds (Fagopyrum esculentum) [75] and hemp seeds [73] when different apparatus were used.

Concerning the treated wheat flour, plasma may kill the unwanted adult beetles and affects its functional properties, producing the qualitatively better dough. So far, there are no attempts with other types of flour to obtain the necessary comparison.

\section{Conclusion}

Plasma decontamination of wheat grains has a great potential to be applied in practice. Reviewed works clearly demonstrate that the plasma causes effective decontamination from bacteria, fungi, and insect pests with minimal damage of grains. Moreover, due to inactivation of several enzymes, plasma treatment can enhance the grain shelf life. Other works demonstrated not only the enhancement of germination and initial state of growth, albeit they suggested a small increase in the final yield. Concerning the treated flour, plasma may kill the adult beetles and affects its functional properties, producing the qualitatively better dough.

It can be stated that NTP treatment of wheat grains has a great potential to be applied in the food industry. The NTP can be used in wheat grain surface disinfection, grain germination and vitality improving, and wheat flour modification and disinfection. The paper brings structured overview of existing knowledge in this area.

\section{Conflicts of Interest}

The authors declare that there are no conflicts of interest regarding the publication of this paper.

\section{Acknowledgments}

This survey was supported by the Charles University Research Program (PROGRES Q25).

\section{References}

[1] V. Scholtz, J. Pazlarova, H. Souskova, J. Khun, and J. Julak, "Nonthermal plasma-A tool for decontamination and disinfection," Biotechnology Advances, vol. 33, no. 6, pp. 11081119, 2015.
[2] N. N. Misra, S. Kaur, B. K. Tiwari, A. Kaur, N. Singh, and P. J. Cullen, "Atmospheric pressure cold plasma (acp) treatment of wheat flour," Food Hydrocolloids, vol. 44, pp. 115-121, 2015.

[3] N. Khamsen, D. Onwimol, N. Teerakawanich et al., "Rice (Oryza sativa L.) seed sterilization and germination enhancement via atmospheric hybrid nonthermal discharge plasma," ACS Applied Materials and Interfaces, vol. 8, no. 30, pp. 19268-19275, 2016.

[4] F.-G. C. Ekezie, D.-W. Sun, and J.-H. Cheng, "A review on recent advances in cold plasma technology for the food industry: current applications and future trends," Trends in Food Science and Technology, vol. 69, pp. 46-58, 2017.

[5] A. Cheng, S. Mayes, G. Dalle, S. Demissew, and F. Massawe, "Diversifying crops for food and nutrition security-a case of teff," Biological Reviews, vol. 92, no. 1, pp. 188-198, 2017.

[6] J. Swinnen, S. Burkitbayeva, F. Schierhorn, A. V. Prishchepov, and D. Müller, "Production potential in the "bread baskets" of Eastern Europe and Central Asia," Global Food Security, vol. 14, pp. 38-53, 2017.

[7] L. Loeb, Basic Processes of Gaseous Electronics, University of California Press, Berkeley, CA, USA, 1960.

[8] H. Raether, Electron Avalanches and Breakdown in Gases, Butterworth, London, UK, 1964.

[9] A. Fridman and L. Kennedy, Plasma Physics and Engineering, Taylor \& Francis, New York, NY, USA, 2004.

[10] M. Laroussi, M. G. Kong, G. Morfill, and W. Stolz, Plasma Medicine, Cambridge University Press, Cambridge, UK, 2012.

[11] C. Tendero, C. Tixier, P. Tristant, J. Desmaison, and P. Leprince, "Atmospheric pressure plasmas: a review," Spectrochimica Acta Part B: Atomic Spectroscopy, vol. 61, no. 1, pp. 2-30, 2006.

[12] Y. Raizer, Gas Discharge Physics, Springer-Verlag, Berlin, Germany, 1991.

[13] J. Khun, V. Scholtz, P. Hozák, P. Fitl, and J. Julák, "Various dcdriven point-to-plain discharges as non-thermal plasma sources and their bactericidal effects," Plasma Sources Science and Technology, vol. 27, no. 6, article 065002, 2018.

[14] K. Kostov, V. Rocha, C. Koga-Ito et al., "Bacterial sterilization by a dielectric barrier discharge (dbd) in air," Surface and Coatings Technology, vol. 204, no. 18-19, pp. 2954-2959, 2010.

[15] Y. A. Lebedev, "Microwave discharges: generation and diagnostics," in Journal of Physics: Conference Series, vol. 257, p. 012016, 2010.

[16] M. Laroussi and T. Akan, "Arc-free atmospheric pressure cold plasma jets: a review," Plasma Processes and Polymers, vol. 4, no. 9, pp. 777-788, 2007.

[17] V. Scholtz and J. Julák, "The "cometary" discharge, a possible new type of dc electric discharge in air at atmospheric pressure, and its bactericidal properties," in Journal of Physics: Conference Series, vol. 223, article 012005, 2010.

[18] V. Scholtz and J. Julak, "Plasma jetlike point-to-point electrical discharge in air and its bactericidal properties," IEEE Transactions on Plasma Science, vol. 38, no. 8, pp. 1978-1980, 2010.

[19] V. Scholtz, E. Kvasničková, and J. Julák, "Microbial inactivation by electric discharge with metallic grid," Acta Physica Polonica A, vol. 124, no. 1, 2013.

[20] J. Julák, V. Scholtz, and E. Vaňková, "Medically important biofilms and non-thermal plasma," World Journal of Microbiology and Biotechnology, vol. 34, no. 12, p. 178, 2018.

[21] D. Graves, "The emerging role of reactive oxygen and nitrogen species in redox biology and some implications for plasma 
applications to medicine and biology," Journal of Physics D: Applied Physics, vol. 45, no. 26, article 263001, 2012.

[22] S. Kelly and M. Turner, "Atomic oxygen patterning from a biomedical needle-plasma source," Journal of Applied Physics, vol. 114, no. 12, 2013.

[23] J. T. Snelson, Grain Protectants, Australian Centre for International Agricultural Research, Canberra, Australia, 1987.

[24] G. P. Georghiou and A. Lagunes-Tejeda, The Occurrence of Resistance to Pesticides in Arthropods, FAO, Rome, Italy, 1991.

[25] L. Věchet and B. Šerá, "Effectiveness of both synthetic compounds and biological extracts against powdery mildew (Blumeria graminis f. sp. tritici) on winter wheat," Agrociencia, vol. 49, no. 1, 2015.

[26] K. F. Khattak and T. J. Simpson, "Effect of gamma irradiation on the antimicrobial and free radical scavenging activities of glycyrrhiza glabra root," Radiation Physics and Chemistry, vol. 79, no. 4, pp. 507-512, 2010.

[27] G. H. F. Santos, E. B. Silva, B. L. Silva, K. X. F. R. Sena, and C. S. A. Lima, "Influence of gamma radiation on the antimicrobial activity of crude extracts of Anacardium occidentale L., anacardiaceae, rich in tannins," Revista Brasileira de Farmacognosia, vol. 21, no. 3, pp. 444-449, 2011.

[28] C. Hernández-aguilar, A. Domínguez-pacheco, A. Cruz-Orea et al., "Bioestimulación láser en semillas y plantas," Gayana Botánica, vol. 73, no. 1, pp. 132-149, 2016.

[29] M. Ito, J.-S. Oh, T. Ohta, M. Shiratani, and M. Hori, "Current status and future prospects of agricultural applications using atmospheric-pressure plasma technologies," Plasma Processes and Polymers, vol. 15, no. 2, article 1700073, 2018.

[30] S.K. Pankaj, Z. Wan, and K.M. Keener, "Effects of Cold Plasma on Food Quality: A Review," Foods, vol. 7, no. 1, p. 4, 2018.

[31] B. Šerá and M. Šerý, "Non-thermal plasma treatment as a new biotechnology in relation to seeds, dry fruits, and grains," Plasma Science and Technology, vol. 20, no. 4, article 044012, 2018.

[32] L. K. Randeniya and G. J. J. B. de Groot, "Non-thermal plasma treatment of agricultural seeds for stimulation of germination, removal of surface contamination and other benefits: a review," Plasma Processes and Polymers, vol. 12, no. 7, pp. 608-623, 2015.

[33] K. Kučerová, M. Henselová, L. Slováková, and K. Hensel, "Effects of plasma activated water on wheat: germination, growth parameters, photosynthetic pigments, soluble protein content, and antioxidant enzymes activity," Plasma Processes and Polymers, vol. 16, no. 3, article 1800131, 2019.

[34] A. Laca, Z. Mousia, M. Díaz, C. Webb, and S. S. Pandiella, "Distribution of microbial contamination within cereal grains," Journal of Food Engineering, vol. 72, no. 4, pp. 332338, 2006.

[35] L. Kordas, W. Pusz, T. Czapka, and R. Kacprzyk, "The effect of low-temperature plasma on fungus colonization of winter wheat grain and seed quality," Polish Journal of Environmental Studies, vol. 24, no. 1, 2015.

[36] A. Los, D. Ziuzina, S. Akkermans et al., "Improving microbiological safety and quality characteristics of wheat and barley by high voltage atmospheric cold plasma closed processing," Food Research International, vol. 106, pp. 509-521, 2018.

[37] A. Zahoranová, M. Henselová, D. Kaliňáková et al., "Effect of cold atmospheric pressure plasma on the wheat seedlings vigor and on the inactivation of microorganisms on the seeds surface," Plasma Chemistry and Plasma Processing, vol. 36, no. 2, pp. 397-414, 2016.
[38] D. Ziuzina, A. Los, S. Akkermans et al., "Modelling microbiological and quality marker responses to enhance cold plasma cereal grain processing," in Proceedings of the 10th International Conference on Simulation and Modelling in the Food and Bio-Industry 2018, FOODSIM 2018, pp. 229-234, Ghent, Belgium, April 2018.

[39] B.-G. Rusu, V. Postolache, I.-G. Cara et al., "Method of fungal wheat seeds disease inhibition using direct exposure to aid cold plasma," Romanian Journal of Physics, vol. 63, p. 905, 2018.

[40] D. Butscher, D. Zimmermann, M. Schuppler, and P. Rudolf von Rohr, "Plasma inactivation of bacterial endospores on wheat grains and polymeric model substrates in a dielectric barrier discharge," Food Control, vol. 60, pp. 636-645, 2016.

[41] M. Shahrzad, I. Sohrab, D. Davoud, T. Siavash, and S. Mahmoud, "The effect of non-thermal plasma to control of stored product pests and changes in some characters of wheat materials," Journal of Biodiversity and Environmental Sciences, vol. 7, no. 5, pp. 150-156, 2015.

[42] M. M. Rahman, S. A. Sajib, M. S. Rahi et al., "Mechanisms and signaling associated with lpdbd plasma mediated growth improvement in wheat," Scientific Reports, vol. 8, no. 1, 2018.

[43] B. Sera, P. Spatenka, M. Sery, N. Vrchotova, and I. Hruskova, "Influence of plasma treatment on wheat and oat germination and early growth," IEEE Transactions on Plasma Science, vol. 38, no. 10, pp. 2963-2968, 2010.

[44] Q. Guo, Y. Meng, G. Qu et al., "Improvement of wheat seed vitality by dielectric barrier discharge plasma treatment," Bioelectromagnetics, vol. 39, no. 2, pp. 120-131, 2018.

[45] Y. Li, T. Wang, Y. Meng et al., "Air atmospheric dielectric barrier discharge plasma induced germination and growth enhancement of wheat seed," Plasma Chemistry and Plasma Processing, vol. 37, no. 6, pp. 1621-1634, 2017.

[46] N. C. Roy, M. M. Hasan, M. R. Talukder, M. D. Hossain, and A. N. Chowdhury, "Prospective applications of low frequency glow discharge plasmas on enhanced germination, growth and yield of wheat," Plasma Chemistry and Plasma Processing, vol. 38, no. 1, pp. 13-28, 2018.

[47] D. Dobrin, M. Magureanu, N. B. Mandache, and M.-D. Ionita, "The effect of non-thermal plasma treatment on wheat germination and early growth," Innovative Food Science and Emerging Technologies, vol. 29, pp. 255-260, 2015.

[48] N. C. Roy, M. M. Hasan, A. H. Kabir, M. A. Reza, M. R. Talukder, and A. N. Chowdhury, "Atmospheric pressure gliding arc discharge plasma treatments for improving germination, growth and yield of wheat," Plasma Science and Technology, vol. 20, no. 11, article 115501, 2018.

[49] M. Braşoveanu, M. Nemţanu, C. Surdu-Bob, G. Karaca, and I. Erper, "Effect of glow discharge plasma on germination and fungal load of some cereal seeds," Romanian Reports in Physics, vol. 67, no. 2, pp. 617-624, 2015.

[50] M. Henselová, L. Slováková, M. Martinka, and A. Zahoranová, "Growth, anatomy and enzyme activity changes in maize roots induced by treatment of seeds with low-temperature plasma," Biologia, vol. 67, no. 3, pp. 490-497, 2012.

[51] A. E. Dubinov, E. R. Lazarenko, and V. D. Selemir, "Effect of glow discharge air plasma on grain crops seed," IEEE transactions on plasma science, vol. 28 , no. 1, pp. 180-183, 2000.

[52] Y.-K. Jo, J. Cho, T.-C. Tsai et al., “A non-thermal plasma seed treatment method for management of a seedborne fungal pathogen on rice seed," Crop Science, vol. 54, no. 2, pp. 796-803, 2014. 
[53] C. Shao, D. Wang, X. Tang, L. Zhao, and Y. Li, "Stimulating effects of magnetized arc plasma of different intensities on the germination of old spinach seeds," Mathematical and Computer Modelling, vol. 58, no. 3-4, pp. 814-818, 2013.

[54] C. Nalwa, A. K. Thakur, A. Vikram, R. Rane, and A. Vaid, "Studies on plasma treatment and priming of seeds of bell pepper (Capsicum annuum L.)," Journal of Applied and Natural Science, vol. 9, no. 3, pp. 1505-1509, 2017.

[55] R. Zhou, R. Zhou, X. Zhang et al., "Effects of atmosphericpressure $\mathrm{n}$, he, air, and o 2 microplasmas on mung bean seed germination and seedling growth," Scientific Reports, vol. 6, no. 1, p. 32603, 2016.

[56] V. Kostin and V. Yermokhin, "Improvement of sowing quality ofspring wheat seed in the result of their processing with physical factors," in Proceedings of the Abstract 1st AllUnion Meeting (Application of Physical and Chemical Mutagenesis in Agriculture), p. 13, Kishinev, USSR, 1987.

[57] Z. Bychkova, V. Levin, and V. Khlebnu, "Metabolism change in seeds at physical factors effect," in Proceedings of the $A b$ stract 1st All-Union Meeting (Application of Physical and Chemical Mutagenesis in Agriculture), p. 40, Kishinev, USSR, 1987.

[58] J. Jiafeng, H. Xin, L. Ling et al., "Effect of cold plasma treatment on seed germination and growth of wheat," Plasma Science and Technology, vol. 16, no. 1, pp. 54-58, 2014.

[59] Y. Meng, G. Qu, T. Wang, Q. Sun, D. Liang, and S. Hu, "Enhancement of germination and seedling growth of wheat seed using dielectric barrier discharge plasma with various gas sources," Plasma Chemistry and Plasma Processing, vol. 37, no. 4, pp. 1105-1119, 2017.

[60] B. Zhang, R. Li, and J. Yan, "Study on activation and improvement of crop seeds by the application of plasma treating seeds equipment," Archives of biochemistry and biophysics, vol. 655, pp. 37-42, 2018.

[61] M. Gidea, M. Magureanu, R. Teodorescu, L. Iosub, and D. Cimpoceriu, "The impact of plasma treatment over wheat seeds," in Proceedings of the 17th International Multidisciplinary Scientific GeoConference SGEM Conference, pp. 361368, Albena, Bulgaria, June-July 2017.

[62] A. Los, D. Ziuzina, D. Boehm, P. J. Cullen, and P. Bourke, "Investigation of mechanisms involved in germination enhancement of wheat (triticum aestivum) by cold plasma: effects on seed surface chemistry and characteristics," Plasma Processes and Polymers, vol. 16, no. 4, article 1800148, 2019.

[63] H. Tolouie, M. A. Mohammadifar, H. Ghomi, A. S. Yaghoubi, and M. Hashemi, "The impact of atmospheric cold plasma treatment on inactivation of lipase and lipoxygenase of wheat germs," Innovative Food Science and Emerging Technologies, vol. 47, pp. 346-352, 2018.

[64] A. Iranbakhsh, N. O. Ardebili, Z. O. Ardebili, M. Shafaati, and M. Ghoranneviss, "Non-thermal plasma induced expression of heat shock factor a4a and improved wheat (Triticum aestivum L.) growth and resistance against salt stress," Plasma Chemistry and Plasma Processing, vol. 38, no. 1, pp. 29-44, 2018.

[65] Z. He, Y. Wang, J. Wang, and C. Tang, "Influence of cold plasma treatment on ear characters and group quality of wheat," in Proceedings of the 2016 ASABE Annual International Meeting, p. 1, American Society of Agricultural and Biological Engineers, Orlando, FL, USA, July 2016.

[66] R. Mahendran, "Effect of cold plasma on mortality of tribolium castaneum on refined wheat flour," in Proceedings of the 10th International Conference on Controlled Atmosphere and Fumigation in Stored Products (CAF 2016), pp. 7-11, New Delhi, India, November 2016.

[67] N. Bahrami, D. Bayliss, G. Chope, S. Penson, T. Perehinec, and I. D. Fisk, "Cold plasma: a new technology to modify wheat flour functionality," Food Chemistry, vol. 202, pp. 247-253, 2016.

[68] R. Mandal, A. Singh, and A. P. Singh, "Recent developments in cold plasma decontamination technology in the food industry," Trends in Food Science and Technology, vol. 77, pp. 21-31, 2018.

[69] R. Thirumdas, A. Kothakota, U. Annapure et al., "Plasma activated water (paw): chemistry, physico-chemical properties, applications in food and agriculture," Trends in Food Science and Technology, vol. 77, pp. 21-31, 2018.

[70] S. Hati, M. Patel, and D. Yadav, "Food bioprocessing by nonthermal plasma technology," Current Opinion in Food Science, vol. 19, pp. 85-91, 2018.

[71] D. Chen, P. Chen, Y. Cheng et al., "Deoxynivalenol decontamination in raw and germinating barley treated by plasma-activated water and intense pulsed light," Food and Bioprocess Technology, vol. 12, no. 2, pp. 246-254, 2019.

[72] A. Zahoranová, L. Hoppanová, J. Šimončicová et al., "Effect of cold atmospheric pressure plasma on maize seeds: enhancement of seedlings growth and surface microorganisms inactivation," Plasma Chemistry and Plasma Processing, vol. 38, no. 5, pp. 969-988, 2018.

[73] B. Sera, M. Sery, B. Gavril, and I. Gajdova, "Seed germination and early growth responses to seed pre-treatment by nonthermal plasma in hemp cultivars (cannabis sativa 1.)," Plasma Chemistry and Plasma Processing, vol. 37, no. 1, pp. 207-221, 2017.

[74] B. Šerá, I. Gajdová, M. Šerý, and P. Špatenka, "New physicochemical treatment method of poppy seeds for agriculture and food industries," Plasma Science and Technology, vol. 15, no. 9, pp. 935-938, 2013.

[75] B. Šerá, I. Gajdová, M. Černák et al., "How various plasma sources may affect seed germination and growth," in Proceedings of the 2012 13th International Conference on Optimization of Electrical and Electronic Equipment (OPTIM), pp. 1365-1370, IEEE, Brasov, Romania, May 2012. 


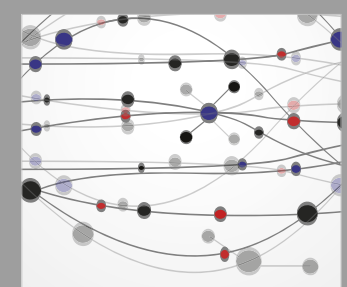

The Scientific World Journal
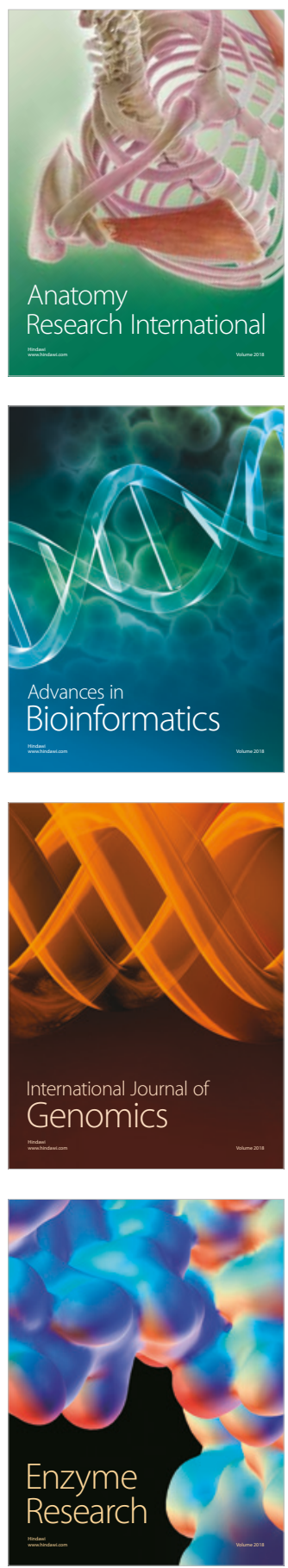
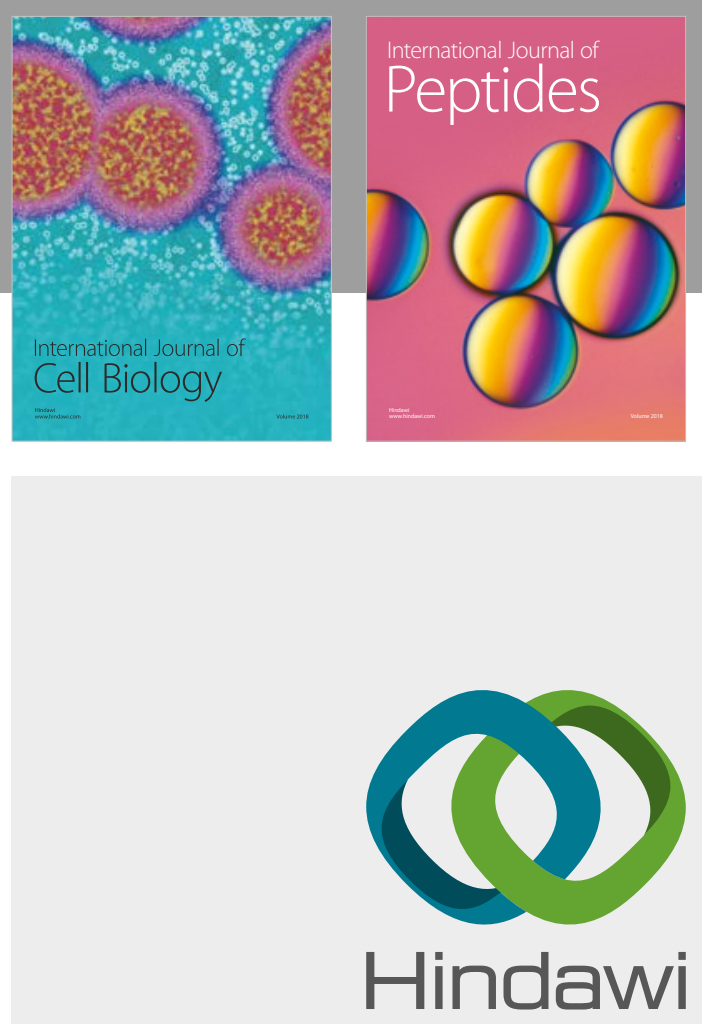

Submit your manuscripts at

www.hindawi.com
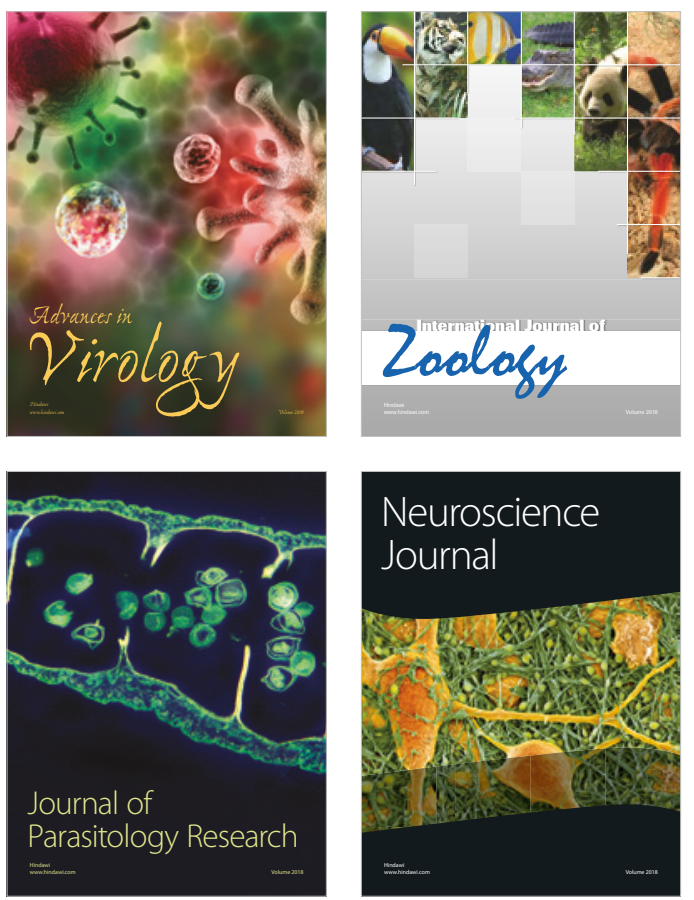
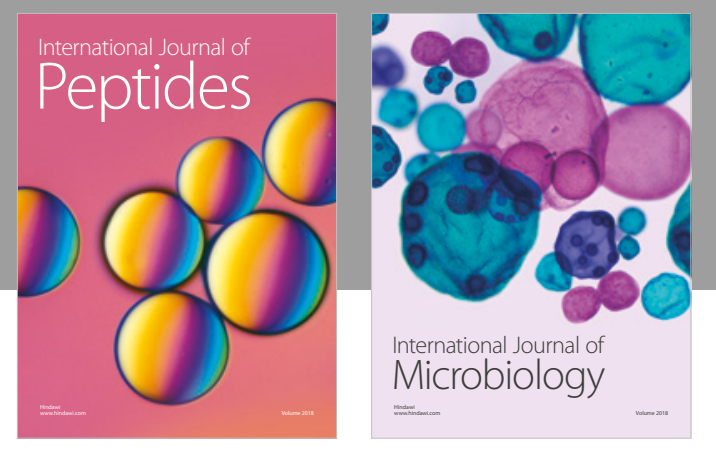

nternational Journal of Microbiology
Journal of
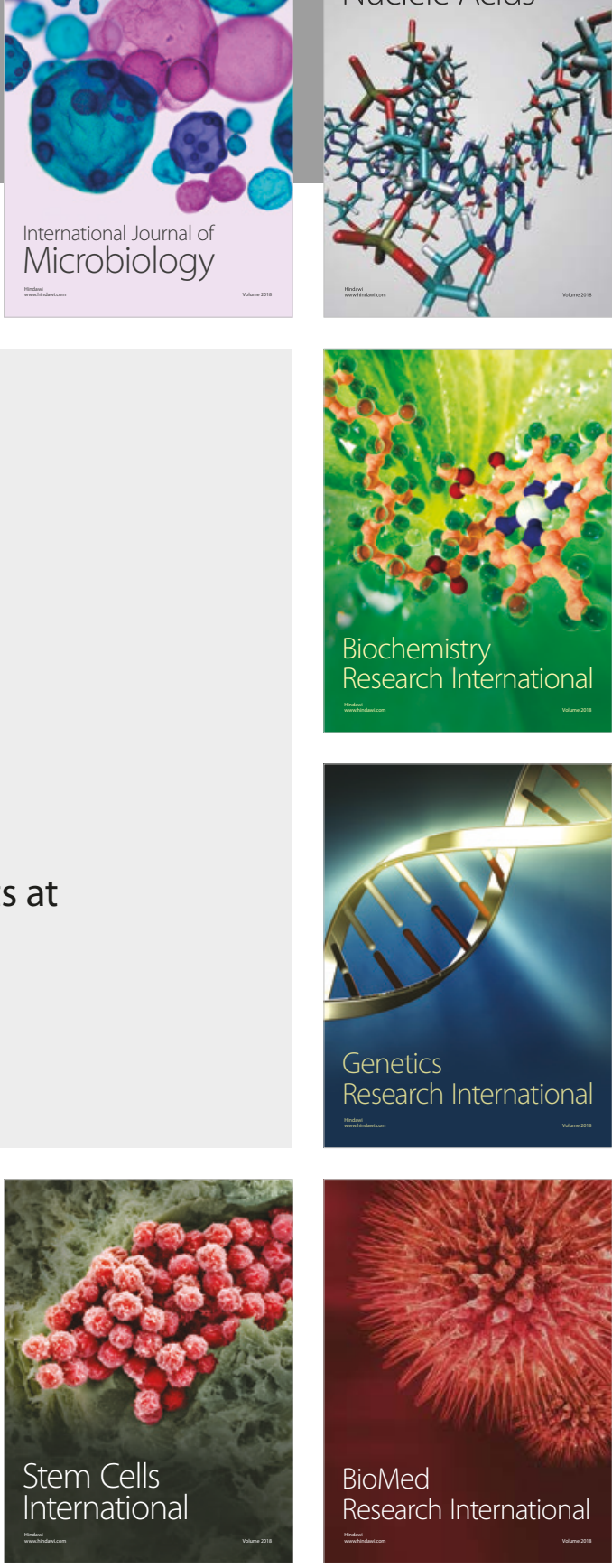
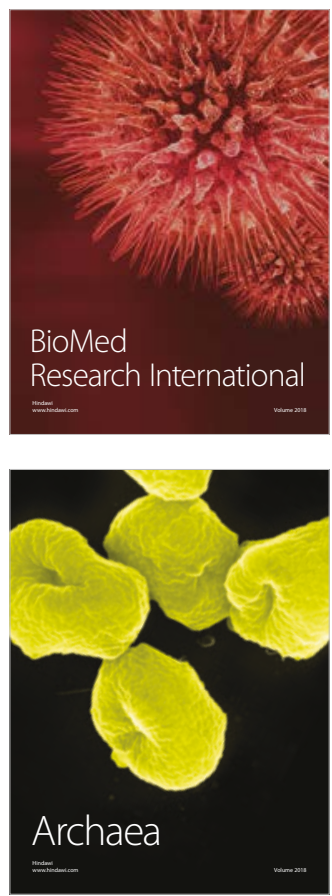